\title{
Contribuições da demografia histórica para o conhecimento da mobilidade socioeconômica e geográfica: uma aproximação ao tema
}

\section{Contributions of historical demography toward the understanding of geographic and socioeconomic mobility: an approach to the theme}

\begin{abstract}
Resumo: Após apresentar um breve apanhado do desenvolvimento da demografia histórica no Brasil para o período 1970-1995, visando evidenciar a ampla abrangência, em termos sociais, econômicos e geográficos, dos estudos efetuados por pesquisadores da aludida área, pretende-se demonstrar como se pode, valendo-se de dados empíricos colhidos em estudos da história demográfica, alcançar informações concernentes à vivência socioeconômica de nossas populações pretéritas, bem como identificar a dispersão pelo espaço geográfico de grupos populacionais e conhecer as condições defrontadas pelos recém-nascidos em face do comportamento econômico das localidades que os albergaram em sua infância.
\end{abstract}

Palavras-chave: Demografia Histórica. Mobilidade Social e Econômica. Mobilidade Espacial.

Abstract: After presenting a brief look at the historical development of Brazil's demography during the period 1970 - 1995, and seeking to show the wide range, in social, economic and geographic terms, of these studies accomplished by researchers in this area, the author will show how it is possible, based on existing empirical studies of demographic history, to access information about the socioeconomic life of the Brazilian populations of the past. Also, to identify the geographic areas of the dispersal of groups of the population and discover the conditions faced by the newly born in the face of the economic conditions of the locations where they were born.

Keywords: Historical demography. Social and economic mobility. Geographic mobility.

\footnotetext{
* Professor Livre-docente aposentado da Faculdade de Economia, Administração e Contabilidade da Universidade de São Paulo. Coordenador do NEHD - Núcleo de Estudos em História Demográfica dos Professores da FEA-USP. Av. Prof. Luciano Gualberto, 908. CEP: 05508-010 - Cidade Universitária, São Paulo, SP. E-mail: idd@terra.com.br
} 


\section{A demografia histórica e seu amplo campo de abrangência}

Não parece absurdo asseverar que toda investigação efetuada na área da história demográfica traz um ou mais elementos informativos sobre a mobilidade social, econômica ou espacial do grupo populacional analisado. Com respeito a tal assertiva talvez seja elucidativo atentar, embora em termos meramente informativos e genéricos, para a geração e o amadurecimento da demografia histórica no Brasil.

Entre os predecessores da demografia histórica destaca-se Gilberto Freyre que, no prefácio de Casa Grande \& Senzala - escrito em Lisboa, em 1931, e revisto em Pernambuco, em 1933 -, já registrava com clareza a relevância da massa documental da qual se serviram, duas décadas depois, os autores aos quais devemos a formulação dos métodos que deram nascimento à demografia histórica. A compreensão acurada das potencialidades carregadas, sobretudo pela documentação eclesiástica, justifica a longa citação extraída do aludido prefácio:

Outros documentos auxiliam o estudioso da história íntima da família brasileira: inventários [...]; cartas de sesmaria, testamentos, correspondências da Corte e ordens reais [...]; pastorais e relatórios de bispos [...]; atas de sessões de Ordens Terceiras, confrarias, santas casas [...], Documentos Interessantes para a História e Costumes de São Paulo, de que tanto se tem servido Afonso de E. Taunay para os seus notáveis estudos sobre a vida colonial em São Paulo; as Atas e o Registro Geral da Câmara de São Paulo; os livros de assentos de batismo, óbitos e casamentos de livres e escravos e os de rol de famílias e autos de processos matrimoniais que se conservam em arquivos eclesiásticos; os estudos de genealogia [...]; relatórios de juntas de higiene, documentos parlamentares, estudos e teses médicas, inclusive as de doutoramento nas Faculdades do Rio de Janeiro e da Bahia; documentos publicados pelo Arquivo Nacional, pela Biblioteca Nacional, pelo Instituto Histórico Brasileiro, na sua Revista, e pelos Institutos de São Paulo, Pernambuco e da Bahia. Tive a fortuna de conseguir não só várias cartas do arquivo da família Paranhos, [...] como o acesso a importante arquivo de família, [...] o do engenho Noruega, que pertenceu por longos anos ao capitão-mor Manuel Tomé de Jesus [...]. Seria para desejar que esses restos de velhos arquivos particulares fossem recolhidos às bibliotecas ou aos museus, e que os eclesiásticos e das Ordens Terceiras fossem convenientemente catalogados. Vários documentos que permanecem em mss. nesses arquivos e bibliotecas devem quanto antes ser publicados. É pena - seja-me lícito observar de passagem - que algumas revistas de História dediquem páginas e páginas à publicação de discursos patrióticos e de crônicas literárias; quando tanta matéria de interesse rigorosamente histórico permanece desconhecida ou de acesso difícil para os estudiosos. (FREYRE, 1933).

Também a anteceder a afirmação da demografia histórica como disciplina autônoma, colocase a monografia de Lucila Herrmann denominada Evolução e estrutura social de Guaratinguetá num período de trezentos anos, datada de fins da década de 1940. Este empreendimento pioneiro - 
Contribuições da demografia histórica para o conhecimento da mobilidade socioeconômica e geográfica: uma aproximação ao tema

calcado, basicamente, em levantamentos populacionais realizados no período colonial - ficou isolado, não conheceu divulgação imediata e não se viu seguido, de pronto, por produções similares.

A década de 1960 vai conhecer os ensaios pioneiros de Luis Lisanti Filho e Maria Luiza Marcílio, cabendo a esta última a autoria da tese intitulada La ville de São Paulo, peuplement et population (1750-1850) d'après les registres paroissiaux et les recensements anciens, texto seminal do qual resultou o reconhecimento, em escala internacional e, sobretudo, em âmbito nacional, da demografia histórica brasileira; dá-se, a contar de sua edição em português, a difusão entre nós dos métodos propostos pelos cientistas franceses criadores deste novo ramo do saber demográfico, situado no amplo campo das ciências sociais. Não é exagero dizer que La ville de São Paulo assinalou o surgimento efetivo da demografia histórica no Brasil.

Ainda nesses momentos iniciais do desenvolvimento da nova disciplina entre nós, vêm à luz as obras de Altiva Pilatti Balhana e de Cecília Maria Westphalen, às quais se seguiram as dissertações elaboradas pelo “grupo” do Paraná; em sua Universidade Federal estruturou-se a pósgraduação em demografia histórica da qual resultou a detecção e o ordenamento sistemático das fontes paranaenses e uma grande quantidade de pesquisas: a maior concentração existente até os anos 1990. Pela primeira vez, demógrafos historiadores colocaram em xeque a “família extensa” e afirmaram a predominância, entre nós, da família nuclear (formada, tão só, por progenitores e seus filhos). Ali também nasce a descrição sistemática das comunidades de imigrantes, dando-se, concomitantemente, o espraiamento da exploração demográfica a qual não se restringiu apenas a comunidades paranaenses, pois abrangeu localidades situadas em Santa Catarina, no Rio Grande do Sul e em Minas Gerais.

O decênio de 1970 ver-se-á irrigado por substancial volume de contestações inovadoras direcionadas a distintas problemáticas e cobrindo novas áreas do território brasileiro. Luiz R. B. Mott volta-se para o Nordeste (Piauí e Sergipe); a ele creditamos o fato de haver questionado abertamente algumas alegações até então tidas como “verdades” inquestionáveis, pensamos aqui no numeroso contingente de pequenos proprietários de cativos, na existência da escravidão na área dominada pela pecuária no Nordeste e na questão do absenteísmo dos proprietários de gado de tal região. Dessa mesma década são as perquirições de Katia M. de Queirós Mattoso e de Stuart B. Schwartz para a Bahia; a monografia de Johildo Lopes de Athayde para Salvador; os frutos dos doutorados de Pedro Carvalho de Mello e de Robert W. Slenes, os quais devotaram particular cuidado à massa escrava existente no Brasil; cabendo a Herbert S. Klein ocupar-se do tráfico 
negreiro intercontinental. A preocupação com as populações mineiras e a ênfase emprestada aos distintos segmentos populacionais característicos da sociedade colonial brasileira (livres, forros e escravos) marcam as publicações de Donald Ramos e Iraci Costa; já a estrutura de posse dos cativos e a relevância dos "pequenos escravistas" consubstanciam o interesse maior de um pioneiro desses tópicos: Francisco V. Luna, que escrutinou os dados de Minas Gerais. Stuart B. Schwartz, por seu turno, buscou caracterizar a estrutura de posse de escravos existentes na Bahia. A relevância deste assunto levou Francisco V. Luna e Iraci Costa a estendê-lo às áreas de São Paulo e do Paraná.

Igualmente, na década de 1970, os agregados e a família mereceram tratamento especial de Eni de Mesquita Samara - que se ocupou dos agregados e estendeu para a família paulista os resultados concernentes ao Paraná e a Minas Gerais -, de Elizabeth Anne Kuznesof e de Alida Christine Metcalf.

Ao fim do decênio de 1970 e início do seguinte, deu-se a extensão dos olhares dos demógrafos historiadores para regiões que permaneciam inexploradas, assim como se aplicaram novas abordagens para captar o evolver populacional das áreas contempladas anteriormente. O rol de especialistas, embora longo, não pode ser descurado: Norte (Ciro Flamarion Santana Cardoso); Paraíba (Elza Régis de Oliveira, Diana Soares de Galliza); Goiás (Eurípedes Antônio Funes, Maria de Souza França); Rio de Janeiro (Eulália Maria Lahmeyer Lobo). Clotilde A. Paiva e Beatriz Ricardina de Magalhães versaram sobre Minas Gerais; Horacio Gutiérrez dedicou-se de modo inovador ao Paraná; Maria Nely dos Santos discorreu sobre Sergipe enquanto o Piauí recebeu a atenção de Miridan Brito Knox. Na década de 1980, Elizabeth Darwiche Rabello, Carlos de Almeida Prado Bacellar e Ana Sílvia Volpi Scott empenharam-se em deslindar as distintas facetas das elites paulistas. Nessa última década, retomou-se, com base numa perspectiva renovada, em nível qualitativo superior e em termos quantitativos mais sofisticados, a linha aberta por Lucila Herrmann; qual seja, a de se escrever, emprestando-se preeminência aos elementos demográficos e econômicos, a história regional, quase sempre relegada a uns poucos abnegados sem formação acadêmica sofisticada. Em linha científica refinada enquadram-se o projeto de esquadrinhamento sistemático da evolução demoeconômica de Campinas, de Peter L. Eisenberg, os escritos sobre a Bahia de Stuart B. Schwartz e o paradigmático Caiçara, de Maria Luiza Marcílio.

A família escrava passa a ser reconhecida, no segundo lustro dos anos 1970 e no correr do decênio de 1980. O trabalho de Richard Graham distingue-se como pioneiro. Segue-se artigo de Francisco V. Luna \& Iraci Costa sobre a família escrava em Vila Rica. Logo após, veio a lume a importantíssima publicação de Robert W. Slenes sobre a família escrava em Campinas. A partir daí, 
Contribuições da demografia histórica para o conhecimento da mobilidade socioeconômica e geográfica: uma aproximação ao tema

surgem muitos ensaios novos, produzidos por Iraci Costa \& Horacio Gutiérrez, Alida Christine Metcalf, Iraci Costa \& Robert W. Slenes \& Stuart B. Schwartz, Gilberto Guerzoni Filho \& Luiz Roberto Netto, João Luís R. Fragoso \& Manolo G. Florentino, José Flávio Motta, Iraci Costa \& Nelson Nozoe, Francisco V. Luna, Ana Sílvia Volpi Scott \& Carlos de Almeida Prado Bacellar; neste quadro coloca-se, também, a exposição sobre casamentos mistos devida a Eliana Maria Réa Goldschmidt.

Nessa mesma quadra de 1980, elaboraram-se novas indagações centradas na família. Maria Sílvia C. Beozzo Bassanezi privilegia a família de colonos do café; Lucila Reis Brioschi disseca genealogias; José Luiz de Freitas contesta o “mito” da família extensa; Katia M. de Queirós Mattoso estuda a família baiana e chega a conclusões análogas às válidas para Minas Gerais, São Paulo e Paraná; Renato Pinto Venancio discute a fundo a questão dos enjeitados; Maria Beatriz Nizza da Silva discorre sobre o sistema de casamentos no Brasil colonial, ao passo que Linda Lewin dedica tese a este último objeto.

No início dos anos 90, vários projetos estavam em andamento. Alguns itens originais foram propostos (reconhecimento demoeconômico dos não-proprietários de escravos, Iraci Costa; movimentos migratórios de nordestinos, Nelson Nozoe \& Eni de Mesquita Samara \& Maria Sílvia C. Beozzo Bassanezi; crescimento vegetativo da massa escrava, H. Gutiérrez \& C. A. Paiva; preço de escravos, Nilce Rodrigues Parreira) e novas áreas são incorporadas (entre outras: Sorocaba, Carlos de Almeida Prado Bacellar; Bananal, José Flávio Motta e Litoral Norte de São Paulo, Ramón V. G. Fernández). Correlatamente, define-se a preocupação com os rumos da demografia histórica brasileira: Quais os objetos a enfocar? Não se mostram necessárias tentativas de generalização e de teorização mais consequentes? Como incorporar a nossas indagações áreas e/ou fases cruciais de nossa economia (nordeste açucareiro, zona do café para o segundo meado do século XIX etc.)?

Nem sempre foi possível, nesta abertura, seguir estritamente a perspectiva cronológica, pois alguns tópicos viram-se concebidos simultaneamente e/ou interpenetraram-se no tempo. De outra parte, algumas criações das mais expressivas precisam ser "encaixadas” na revisão histórica aqui esboçada, tomamos como exemplos a classificação dos setores e ramos de atividades econômicas, de Iraci Costa e Nelson Nozoe; o trabalho de Tarcísio do Rego Quirino, sobre os habitantes do Brasil no fim do século XVI; a pesquisa de Carlos Roberto A. dos Santos sobre preços de escravos no Paraná; e a obra intitulada Slave life in Rio de Janeiro, 1808-1850, de Mary C. Karash. Enfim, 
muito poderia ser acrescentado ao elenco aqui arrolado. De outra parte, cumpre lembrar que a encerramos no início dos anos 1990, porque ir avante seria temeroso, pois nos lustros mais recentes procedeu-se à feitura de milhares de dissertações, teses, livros e artigos sobre nossa história demográfica.

\section{Ainda nos resta um longo caminho a percorrer}

Assim, conquanto a descrição acima indicada seja sucinta e parcial, parece-nos bastante para revelar o vasto campo abrangido pela demografia histórica e o fato de que se deu no Brasil um verdadeiro transbordamento com relação aos temas estritamente demográficos, vale dizer, por haver grandes lacunas quanto ao conhecimento mais pormenorizado de nosso passado histórico, os demógrafos historiadores brasileiros sentiram-se impelidos a descobrir (redescobrir) e a reescrever (escrever) nossa história econômica, social, das mentalidades, das instituições etc.; destarte, o exame de variáveis demográficas definiu-se como uma ampla porta de entrada para a história entendida em todas suas dimensões. Note-se, além disso, que a inexistência, entre nós, de uma história regional solidamente embasada, tem levado alguns demógrafos historiadores a tomar como sua a tarefa de promovê-la.

Muito embora, como visto, nossos demógrafos historiadores tenham estendido seus estudos no espaço, no tempo e no que tange à vasta temática abarcada por nossa disciplina, ainda nos defrontamos com um longo caminho a percorrer nas três dimensões ora aventadas. Assim, existem áreas geográficas pouco estudadas, sobretudo o Norte e o Nordeste; o século XVI ainda nos escapa, bem como o conhecimento mais circunstanciado da segunda metade do século XIX; muitos temas até agora não mereceram nossa atenção e carecemos de perquirições voltadas para a generalização dos achados já revelados. Destarte, não é errôneo afirmar-se que teremos de formular padrões capazes de lançar luz sobre as evidências pontuais já levantadas, seremos compelidos a buscar as regularidades ainda não desveladas, assim como nos caberá tentar discriminar claramente as causas comuns que se encontram nas raízes dos elementos empíricos já fixados; enfim, até os dias correntes, não chegamos a uma visão teórica de conjunto da formação de nossas populações. Em face de tais óbices, e norteados pelo título em epígrafe, vemo-nos obrigados, na exposição vertente, a apontar, tão somente, alguns contributos da demografia histórica com respeito a proposições tradicionais de nossa historiografia, as quais já estão a conhecer uma profunda revisão. 
Contribuições da demografia histórica para o conhecimento da mobilidade socioeconômica e geográfica: uma aproximação ao tema

\section{Os africanos no espaço geográfico brasileiro}

Tomemos como exemplo inicial o caso da dispersão do elemento africano no espaço geográfico brasileiro.

A contar do início do século passado desencadeou-se controvérsia concernente à filiação étnica e/ou linguística dos africanos deslocados de seu continente de origem para o Brasil. Outro ponto de divergência referiu-se à distribuição dos cativos africanos em nosso território.

De acordo com R. Nina Rodrigues (1945) e Arthur Ramos (1937), para aqui dirigiram-se tanto Sudaneses como Bantos. Os primeiros compareceriam amplamente na Bahia e, talvez em escala mais modesta, em Pernambuco e no Maranhão; os Bantos, por seu turno, ocupariam área mais extensa, do Maranhão ao centro e sul do espaço colonial. Estes especialistas vieram pôr cobro ao engano largamente difundido e que perdurou por longo período na historiografia brasileira. Tal erro foi propalado, sobretudo, por viajantes estrangeiros como Spix e Martius (1938); segundo eles, somente os Bantos teriam composto a população negra do Brasil. Lembre-se que a impressão desses visitantes foi endossada por vários de nossos historiadores, entre os quais figuram Sílvio Romero e João Ribeiro.

Já Francisco M. Salzano e Nilton Freire-Maia, ao criticarem a opinião de Nina Rodrigues e Arthur Ramos sobre a dispersão dos africanos no território nacional, salientaram: "há evidência de que o esquema [...] de Nina Rodrigues e Arthur Ramos não correspondia totalmente à realidade dos fatos. Há, por exemplo evidência de caráter histórico e linguístico da presença de largos contingentes de sudaneses em Minas Gerais” (SALZANO; FREIRE-MAIA, 1967, p. 29-30). A corroborar os reparos desses investigadores, incluem-se os materiais oferecidos por Iraci Costa (1976) e por Lucinda C. M. Coelho (1973).

De outra parte, vem-se firmando o consenso de que os Sudaneses foram levados para as Minas Gerias em razão de possuírem conhecimento técnico mais apurado e estarem familiarizados com os misteres da mineração em suas “nações” de origem. Como anotou Charles R. Boxer:

Os mineiros preferiam os 'minas' exportados principalmente de Ajudá, tanto por serem mais fortes e mais vigorosos do que os bantos como porque acreditavam terem eles poder quase mágico para descobrir ouro [...] A procura dos 'minas' também se vê refletida nos registros dos impostos para escravos, fosse para pagamento dos quintos ou para o da capitação. (BOXER, 1969, p. 195). 
As habilidades, as qualificações diferenciais, bem como a adaptabilidade de Bantos e Sudaneses à lide mineratória foram, desde os primórdios da economia do ouro em Minas Gerais, avaliadas distintamente.

O confronto de textos coevos evidencia as mudanças havidas na apreciação desses dois grupos. Em Carta Régia de 1711 lê-se:

Me pareceu resolver que os negros que entrarem neste Estado [Brasil], vindos da Angola, e forem enviados por negócio para as Minas paguem de saída a seis mil réis, [...] e os que forem da Costa da Mina, e se remeterem também para as Minas, paguem três mil réis por cabeça, [...] por serem inferiores, e de menos serviços que os de Angola. (CARTA RÉGIA..., 1929).

Em carta do marquês de Angeja, vice-rei do Brasil, escrita em 1714, revela-se opinião divergente:

Pela cópia do edital que com esta remeto será presente a Vossa Majestade ter-se dado cumprimento ao que foi servido ordenar por esta Provisão e como nela se determina que os negros que viessem de Angola para esta praça e dela fossem por negócio para as Minas pagassem à saída seis mil réis por cabeça, sendo peças da Índia e os da Costa da Mina a três mil réis por serem inferiores e de menos serviços que os de Angola, o que é tanto pelo contrario, que os que vêm da Mina se vendem por preço mais subido por ter mostrado a experiência dos mineiros serem estes mais fortes e capazes para aturar o trabalho a que os aplicam; o que me obrigou a consultar esta matéria com os Ministros, e pessoas de mais inteligência e resolvi que vista a equivocação que houve no valor de uns e outros negros pagassem todos igualmente quatro mil e quinhentos por cabeça [...]. (Citado por Braz do Amaral, in ANAIS DO $1^{\circ}$ CONGRESSO..., p. 676-677).

Em 1725, o Governador da Capitania do Rio de Janeiro voltava ao problema e reafirmava a “superioridade” do elemento Sudanês:

As Minas é certo, que se não podem cultivar senão com negros [...] os negros minas são os de maior reputação para aquele trabalho, dizendo os Mineiros que são os mais fortes, e vigorosos, mas eu entendo que adquiriram aquela reputação por serem tidos por feiticeiros, e têm introduzido o diabo, que só eles descobrem, e pela mesma causa não há Mineiro que se possa viver sem uma negra mina, dizendo que só com elas tem fortuna. (CARTA DO GOVERNADOR..., 1929).

Tais documentos patenteiam que, apesar do engano inicial de avaliação no qual incorreu a Coroa, logo se evidenciou a preferência dos mineiros pelos negros "Mina”. Certamente seu propalado poder diabólico para localizar ouro nada mais era do que o resultado de conhecimentos adquiridos na África.

Visando contribuir para o estudo do assunto em tela, servimo-nos - a fim de mensurarmos a 
Contribuições da demografia histórica para o conhecimento da mobilidade socioeconômica e geográfica: uma aproximação ao tema

quantos chegavam entre nós os Bantos e Sudaneses e para sabermos como se relacionavam os efetivos de cada um desses grupos -, dos registros de óbitos da Freguesia de Nossa Senhora da Conceição de Antônio Dias (doravante FNSCAD), uma das duas existentes, no período colonial, em Vila Rica, atual Ouro Preto (MG), e dos dados empíricos extraídos do arrolamento populacional levado a efeito em Minas Gerais no ano de 1804 (COSTA, 1979) e divulgado por Herculano Gomes Mathias (1969).

Quanto aos documentos de óbitos de Antônio Dias, examinamos o período 1719-1818. Só a partir da segunda década do século XVIII podemos contar com manuscritos contínuos e em bom estado de conservação. Este fato demarcou o limite cronológico inferior do período selecionado para análise. O balizamento superior - final do primeiro quinto do século dezenove - foi escolhido porque, a essa altura, apresentava-se superada a procura do ouro nas Minas Gerais e escoara-se o período que se nos apresenta como de transição da ação exploratória para a agrícola. Assim, o lapso temporal contemplado abarca o surto mineratório, seu auge e decadência, englobando, ademais, as eventuais repercussões socioeconômicas, na paróquia em foco, do reflorescimento agrícola vivenciado pela Colônia a partir do derradeiro quartel do século XVIII.

Com base na fonte paroquial mencionada, distribuímos os elementos africanos em grandes grupos correspondentes a Bantos e Sudaneses. Evidentemente, computamos apenas os indivíduos para os quais constou explicitamente a "nação" de origem. Embora possam ter ocorrido omissões imputáveis aos clérigos responsáveis pelos assentos de óbitos, tal corpo documental apresenta-se como ótimo repositório de dados numéricos e qualitativos mediante os quais se pode descrever a composição da massa de negros deslocada para a área mineratória.

Preservada a ideia de que nenhum dos raciocínios comparativos expendidos no corpo destes apontamentos tem caráter qualitativo, impõe-se assinalar que os resultados da indagação descrita acima não deixam dúvidas quanto ao marcante comparecimento dos Sudaneses em Minas; no século estudado (1719-1818), registrou-se a predominância, por pequena margem, do elemento Sudanês (52,1\%) sobre o Banto (47,9\%).

A fim de captar possíveis mudanças no curso do tempo, subdividimos o espaço temporal analisado em quatro subperíodos de 25 anos cada. O confronto dos porcentuais indica alterações de monta no correr do tempo. Assim, nos três primeiros subperíodos mostrou-se majoritário o elemento Sudanês; já no quartel final (1794-1818) predominaram os Bantos (Cf. Tabela 1). 
Tabela 1 - REPARTIÇÃO DOS ESCRAVOS AFRICANOS SEGUNDO A ORIGEM (FNSCAD, 1719-1818)

\begin{tabular}{|c|c|c|c|c|}
\hline Grandes Grupos e "Nações” & 1719-1743 & $1744-1768$ & 1769-1793 & $1794-1818$ \\
\hline \multicolumn{5}{|l|}{ SUDANESES } \\
\hline Mina & 42 & 391 & 688 & 394 \\
\hline Cabo Verde & 3 & 13 & 17 & 2 \\
\hline Nagô & 1 & 8 & 15 & 4 \\
\hline Outras & 8 & 14 & 8 & --- \\
\hline Total de Sudaneses & 54 & 426 & 728 & 400 \\
\hline \multicolumn{5}{|l|}{ BANTOS } \\
\hline Bengala & 10 & 30 & 43 & 23 \\
\hline Angola & 19 & 195 & 447 & 521 \\
\hline Congo & 7 & 7 & 16 & 23 \\
\hline Cambunda & 1 & 1 & 2 & 9 \\
\hline Moçambique & 2 & 7 & 1 & --- \\
\hline Outras & 11 & 40 & 44 & 18 \\
\hline Total de Bantos & 50 & 280 & 553 & 594 \\
\hline Total Geral & 104 & 706 & 1.281 & 994 \\
\hline
\end{tabular}

Fonte: COSTA, 1979, p. 239.

No que tange às "nações” de origem, predominaram, entre os Sudaneses, os "Mina”, "Nagô" e “Cabo Verde”; quanto aos Bantos, coube preeminência dos “Angola”, “Bengala” e “Congo”.

Considerando-se o arrolamento populacional efetuado em 1804 e tomados os resultados atinentes a Vila Rica, aspecto da maior importância refere-se à distribuição, segundo faixas etárias, dos cativos integrantes dos grupos étnicos e/ou linguísticos em foco. Nota-se, para Bantos, o predomínio nas faixas inferiores; já a fração de Sudaneses era dominante nas idades mais avançadas (Cf. Tabela 2).

Tabela 2 - REPARTIÇÃO DOS ESCRAVOS AFRICANOS, SEGUNDO A ORIGEM E GRANDES GRUPOS ETÁRIOS(VILA RICA - 1804)

\begin{tabular}{|c|c|c|c|c|}
\hline Faixas Etárias & \multicolumn{2}{|c|}{ Sudaneses } & \multicolumn{2}{c|}{ Bantos } \\
\hline $0-19$ & 5 & $2,90 \%$ & 99 & $10,30 \%$ \\
\hline $20-59$ & 115 & $66,50 \%$ & 779 & $81,10 \%$ \\
\hline 60 e mais anos & 52 & $30,00 \%$ & 80 & $8,30 \%$ \\
\hline Idade ignorada & 1 & $0,60 \%$ & 3 & $0,30 \%$ \\
\hline Total & $\mathbf{1 7 3}$ & $\mathbf{1 0 0} \%$ & $\mathbf{9 6 1}$ & $\mathbf{1 0 0 \%}$ \\
\hline
\end{tabular}

Fonte: COSTA, 1979, p. 248. 
Contribuições da demografia histórica para o conhecimento da mobilidade socioeconômica e geográfica: uma aproximação ao tema

Os Sudaneses, conquanto preferidos pelos mineradores, passaram a entrar na área em apreço segundo taxas decrescentes. Possivelmente, os Bantos, vendidos a preços inferiores, tenham aparecido no mercado de escravos como elemento substitutivo dos Sudaneses. Este fenômeno acarretou o "envelhecimento" da massa de cativos Sudaneses, o que implicou o desproporcionado peso relativo de ambos os grupos no conjunto dos vivos, por um lado, e entre os mortos, por outro. Assim, em 1804, os escravos distribuíam-se em Bantos e Sudaneses, de acordo com os pesos 84,7\% e 15,3\%, respectivamente. Quanto aos óbitos, a repartição manifestava-se significativamente diversa - para o mesmo ano, a proporção dos Bantos limitou-se a 71,9\% e a dos Sudaneses alcançou 28,1\%. Pode imputar a causa dessa desproporção ao fato de que 30,0\% destes últimos contavam 60 ou mais anos, enquanto apenas 8,3\% dos primeiros achavam-se em igual faixa etária.

A conclusão maior a ser inferida do acima posto é a de que a demografia histórica poderá vir a concorrer largamente para o melhor entendimento da distribuição espacial das populações estabelecidas no Brasil. Evidentemente, muito tempo escoar-se-á até que tenhamos estudos aprofundados sobre cada área de nosso vasto território; se este fato pode levar o desalento a alguns, certamente mostra-se alvissareiro para os que se iniciam na área de nossa formação populacional, pois lhes mostra quantos achados poderão ser colhidos em uma órbita de indagação na qual resta muito a produzir e deslindar.

\section{Sobre a mobilidade socioeconômica}

Passemos à consideração de outro caso exemplar, qual seja, o da mobilidade socioeconômica, constatada nos quadros da economia da mineração no século XVIII. Sabemos tratar-se de um caso muito específico, estreitamente balizado, tanto no tempo - cerca de oito décadas -, como no espaço geográfico, pois nos ocupamos, tão só, de uma paróquia de Vila Rica. Não obstante, parece-nos modelar porque evidencia de maneira palmar o valioso papel que pode ser desempenhado pela demografia histórica, quanto ao conhecimento de nosso passado colonial. Tomaremos, pois, para a Freguesia de Nossa Senhora da Conceição de Antônio Dias, os dados ali preservados com referência à estrutura de posse de escravos e à composição da massa de senhores segundo seu enquadramento em dois dos estratos sociais existentes em nosso período colonial: livres e forros.

O conhecimento da estrutura de posse de cativos, afora lançar luz sobre a estratificação social vigente em qualquer sociedade e encerrar valioso subsídio para o lineamento das práticas 
produtivas de maior significância em cada momento histórico, apresenta-se como elemento altamente relevante para delinear-se o nível relativo de riqueza dos segmentos socioeconômicos em que se pode decompor uma dada comunidade. À vista disto, evidencia-se claramente o substantivo contributo que trará, ao entendimento da aludida sociedade, a identificação do perfil da posse de escravos.

Cremos, além disso, que a estrutura de posse de escravos apresentava elevada correlação com a própria forma como a riqueza se distribuía entre os mineradores. Como escreve Celso Furtado (1968, p.82) “A natureza mesma da empresa mineira não permitia uma ligação à terra do tipo da que prevalecia nas regiões açucareiras. O capital fixo era reduzido, a vida de uma lavra era sempre algo incerto. A empresa estava organizada de forma a poder deslocar-se em tempo relativamente curto. Por outro lado, a elevada lucratividade do negócio induzia a concentrar na própria mineração todos os recursos disponíveis” (Formação econômica do Brasil); ao que nós acrescentaríamos a afirmativa de que estes recursos, em larga medida, alocavam-se na compra de escravos, principal fator de produção utilizado nas tarefas extrativas.

A labuta mineratória possibilitava aos escravos maior mobilidade social vis-à-vis às demais economias do Brasil-colônia. A forma como se realizava a cata do ouro e diamantes possibilitava maior liberdade e iniciativa aos cativos. Por rigoroso que fosse o controle exercido - e o era, especialmente na lavagem do cascalho -, o escravo detinha incomparável responsabilidade na localização das pedras preciosas e das partículas de ouro. Por essa razão, os mineiros tentavam estimular seus escravos concedendo-lhes prêmios pelo produto de suas buscas, donde a grande frequência de alforrias.

Ao cativo, obtida a liberdade, tornava-se fácil dedicar-se à faiscação. Os resultados de seu árduo mister, caso se visse favorecido pela sorte, poderiam proporcionar-lhe os meios para tornarse, ele próprio, um senhor de escravos.

Visando cumprir os objetivos arrolados acima, servimo-nos, mais uma vez, dos lançamentos de óbitos da freguesia de Antônio Dias; foram selecionados para este exercício os seguintes triênios: 1743-45, 1760-62, 1799-1801 e 1809-11. O primeiro situa-se numa quadra na qual florescia a lide exploratória. No segundo, já se revelava declinante a faina aurífera. O penúltimo coloca-se na fase de franca decadência do centro urbano em foco. No triênio 1809-11 achava-se superada a ação mineratória e delineara-se, como frisado acima, a recuperação da economia colonial com base na agricultura.

Quanto à mobilidade socioeconômica, merece realce o comparecimento significativo dos forros no conjunto dos detentores de escravos. Representaram eles nos períodos escolhidos, 
Contribuições da demografia histórica para o conhecimento da mobilidade socioeconômica e geográfica: uma aproximação ao tema

respectivamente: 8,8\%; 14,6\%; 6,9\% e 3,0\% do total de proprietários. Essas cifras evidenciam, ademais, o declínio dos escravistas alforriados sobre o total de senhores; tal decremento, por seu turno, viu-se condicionado, certamente, pela decadência da lida exploratória no núcleo populacional em tela.

Fato igualmente marcante refere-se à distinta constituição da massa escrava pertencente a forros vis-à-vis aquela possuída por livres, os quais, por deterem maior riqueza e poder aquisitivo, voltavam-se, ao que parece, a fainas produtivas - seja pela escala, seja pela natureza - mais exigentes de mão de obra masculina adulta. Esta inferência deriva do confronto, para esses dois segmentos populacionais, da parcela dos óbitos de escravos homens e adultos sobre o total de falecimentos de cativos (Cf. Tabela 3).

Tabela 3 - PORCENTAGENS DE ESCRAVOS ADULTOS DO GÊNERO MASCULINO NO TOTAL DE ÓBITOS DE CATIVOS, SEGUNDO A CONDIÇÃO SOCIAL DOS PROPRIETÁRIOS (FNSCAD, PERÍODOS SELECIONADOS)

\begin{tabular}{|l|r|r|r|r|}
\hline Proprietários & $1743-1745$ & $1760-1762$ & $1799-1801$ & $1809-1811$ \\
\hline Livres & 77,78 & 71,92 & 63,88 & 52,27 \\
\hline Forros & 31,82 & 47,92 & 31,25 & 33,33 \\
\hline
\end{tabular}

Fonte: COSTA, 1981, p. 153.

Ainda no tocante à mobilidade - vista agora sob os prismas social e espacial - evento dos mais eloquentes consiste na queda, no decurso dos anos, da participação dos proprietários livres do gênero masculino e ao dramático incremento da porcentagem de proprietárias do mesmo estrato social. Destarte, compreendido o corpo inteiro de senhores, evidencia-se o continuado decréscimo acima referido; os senhores livres do gênero masculino representaram, nos períodos já assinalados, respectivamente: 87,63\%; 78,80\%; 63,12\% e 62,00\%. Tal declínio viu-se mais do que compensado - considerando-se os triênios extremos aqui computados - pelo aumento correspondente à participação das proprietárias livres; para estas, obedecida a mesma ordem cronológica, anotaramse as seguintes cifras: 3,60\%; 6,64\%; 30,00\% e 35,00\%.

O elemento livre do gênero masculino resultou, pois, como que "substituído” pelo gênero oposto; fenômeno facilmente detectável na Tabela 4. Assim, de uma posição praticamente “monopolizadora”, a proporção de homens reduziu-se drasticamente, não alcançando sequer os dois terços do total de senhores livres; paralelamente, a porcentagem das mulheres, quase decuplicou. 
Tabela 4 - PORCENTUAIS DE PROPRIETÁRIOS, SEGUNDO O GÊNERO, CONSIDERANDOSE O TOTAL DE SENHORES LIVRES (FNSCAD, PERÍODOS SELECIONADOS)

\begin{tabular}{|l|r|r|r|r|}
\hline Proprietários & \multicolumn{1}{|l|}{$1743-1745$} & $1760-1762$ & $1799-1801$ & \multicolumn{1}{|c|}{$1809-1811$} \\
\hline Homens & 96,05 & 92,22 & 67,79 & 63,92 \\
\hline Mulheres & 3,95 & 7,78 & 32,21 & 36,08 \\
\hline
\end{tabular}

Fonte: COSTA, 1981, p. 154.

Um dos fatores explicativos deste processo repousa no movimento emigratório verificado em Vila Rica a partir, sobretudo, dos anos 60 do século XVIII. Em outra publicação (COSTA, 1979), analisamos exaustivamente esse deslocamento populacional no qual predominaram os homens livres; estes, possivelmente acompanhados por seus escravos, demandavam outras áreas do território colonial. Essa migração nos remete à elevada porção de proprietárias viúvas; não dispomos de dados conclusivos, mas, ao que parece, o aumento da quantidade de senhoras livres decorreu, em grande medida, do crescente peso relativo das viúvas no conjunto das donas de cativos. Apenas para o triênio 1809-11 nos foi possível calcular, aproximadamente, a proporção de viúvas sobre o total de proprietárias livres. As viúvas, somavam, no mínimo, 45,7\% das senhoras livres e possuíam, ao menos, $47,7 \%$ da escravaria pertencente a todas as proprietárias livres. Tal fato derivar-se-ia do próprio esmorecimento da vida econômica da urbe. A consequente saída de senhores do gênero masculino fez avolumar-se, no cômputo porcentual, o peso das viúvas certamente com menor propensão a deslocamentos espaciais - herdeiras dos escravos dos esposos.

Atenhamo-nos, agora, aos proprietários forros. Para estes, diferentemente do constatado com referência aos senhores livres, revelou-se majoritário o gênero feminino. Os dados parecem indicar, pois, que a mobilidade socioeconômica mostrava-se maior entre as mulheres forras do que entre o elemento masculino de mesma condição social. De outra parte, com relação aos alforriados, não se patentearam transformações quantitativas capazes de igualar, pela magnitude, aquelas detectadas entre os senhores livres.

Relativamente ao total de proprietários couberam às forras, obedecidos os triênios anotados acima, os seguintes valores: 5,2\%; 8,2\%; 5,6\% e 2,0\%. Aos libertos do gênero masculino tocaram cifras mais modestas: 3,6\%; 6,4\%; 1,3\% e 1,0\%.

Como visto acima, as mulheres predominavam entre os proprietários forros. A nosso ver, esta característica exprime a grande distinção entre livres e libertos. O peso relativo maior do 
Contribuições da demografia histórica para o conhecimento da mobilidade socioeconômica e geográfica: uma aproximação ao tema

gênero feminino vai ilustrado na Tabela 5, da qual se infere, concomitantemente, a diminuta mudança na massa de proprietários forros, considerados os gêneros, vis-à-vis as grandes variações ocorridas no conjunto de senhores livres, fenômeno ao qual já nos referimos.

Tabela 5 - PORCENTUAIS DE PROPRIETÁRIOS, SEGUNDO O GÊNERO, CONSIDERANDOSE O TOTAL DE SENHORES FORROS (FNSCAD, PERÍODOS SELECIONADOS)

\begin{tabular}{|l|r|r|r|r|}
\hline Proprietários & \multicolumn{1}{|l|}{$1743-1745$} & $1760-1762$ & $1799-1801$ & $1809-1811$ \\
\hline Homens & 41,18 & 43,48 & 18,18 & 33,33 \\
\hline Mulheres & 58,82 & 56,52 & 81,82 & 66,67 \\
\hline
\end{tabular}

Fonte: COSTA, 1981, p. 155.

Enumeremos, pois, os principais resultados propiciados pelo estudo dos elementos empíricos aqui apreciados:

1. Marcou-se a presença relevante do elemento forro no conjunto dos proprietários de escravos;

2. Confirmou-se a prevalência, na área em apreço, de uma sociedade permeável à ascensão de elementos alforriados, donde a inexistência de estrita rigidez quanto à estratificação social;

3. Quanto ao gênero dos proprietários forros, contrariamente ao válido para os "não-forros” (livres), predominou o feminino; por sua vez, os proprietários "não-forros" do gênero masculino mostraram-se majoritários no conjunto dos senhores;

4. Evidenciou-se, ademais, declínio da parcela relativa do elemento forro no conjunto de senhores de cativos; fenômeno condicionado, certamente, pela própria decadência da atividade econômica na área em que predominou a mineração.

\section{Contemplando a mobilidade espacial}

Fechado nosso segundo exemplo, passemos a um terceiro. Como avançado, a história demográfica pode contribuir de variadas maneiras para o entendimento dos deslocamentos espaciais, uma delas repousa na observação da origem dos nubentes. Vejamos, pois, como fazê-lo. 
Para esta inquirição escolhemos os assentos de 960 casamentos que uniram cônjuges livres (exclusive forros) na Freguesia de Nossa Senhora da Conceição de Antônio Dias (Vila Rica) no período 1727-1826.

Visando estabelecer as regiões que concorreram para o povoamento de Vila Rica e, ainda, a amplitude dos movimentos migratórios, distribuímos os locais de origem dos esposos em oito categorias. A classificação adotada, segundo círculos centrados em Vila Rica, foi a seguinte:

Categoria 1 - cônjuge nascido ou batizado na Freguesia de Nossa Senhora da Conceição de Antônio Dias.

Categoria 2 - cônjuge nascido ou batizado na Freguesia do Pilar (Vila Rica).

Categoria 3 - cônjuge nascido ou batizado nas vilas, povoações ou freguesias situadas em raio de 50 km em torno de Vila Rica.

Categoria 4 - cônjuge nascido ou batizado em vilas, povoações ou freguesias em área demarcada por raios de 50 e $100 \mathrm{~km}$.

Categoria 5 - cônjuge nascido no Bispado de Mariana, porém em local situado além do raio de $100 \mathrm{~km}$.

Categoria 6 - cônjuge nascido em outros Bispados do Brasil.

Categoria 7 - cônjuge oriundo de Portugal, da Itália, das Ilhas Atlânticas ou da África.

Categoria 8 - cônjuge sem origem especificada.

Os resultados (Cf. Tabela 6) sugerem menor mobilidade das mulheres em face dos homens. Assim, 68,85\% das mulheres enquadraram-se nas categorias 1 e 2 (nascidas e/ou batizadas em Vila Rica), enquanto apenas 38,23\% dos homens encontraram-se em igual situação. De um raio de $100 \mathrm{~km}$ procederam 55,72\% dos homens e 83,65\% das mulheres; 92,19\% destas últimas nasceram ou foram batizadas no Brasil enquanto os homens em igual condição restringiram-se a 66,14\%. A maior estabilidade da massa feminina em face dos homens mostrou-se, pois, iniludível. 
Contribuições da demografia histórica para o conhecimento da mobilidade socioeconômica e geográfica: uma aproximação ao tema

Por outro lado, no fluxo imigratório - proveniente da metrópole e de outras dependências coloniais portuguesas - predominou o elemento masculino (27,8\% do total de cônjuges homens) sobre o feminino (2,7\% do total de esposas).

Tabela 6 - ORIGEM DOS CÔNJUGES LIVRES (EXCLUSIVE FORROS) (FNSCAD, 1727-1826)

\begin{tabular}{|c|c|r|r|r|r|r|}
\hline CATEGORIAS & \multicolumn{3}{|c|}{ HOMENS } & \multicolumn{3}{c|}{ MULHERES } \\
\hline & NOIVOS & \multicolumn{1}{|c|}{$\%$} & \multicolumn{1}{|c|}{ \% AC. } & NOIVAS & \multicolumn{1}{c|}{$\%$} & \multicolumn{1}{c|}{ \% AC. } \\
\hline 1 & 322 & 33,54 & 33,54 & 601 & 62,60 & 62,60 \\
\hline 2 & 45 & 4,69 & 38,23 & 60 & 6,25 & 68,85 \\
\hline 3 & 146 & 15,2 & 53,43 & 123 & 12,82 & 81,67 \\
\hline 4 & 22 & 2,29 & 55,72 & 19 & 1,98 & 83,65 \\
\hline 5 & 45 & 4,69 & 60,41 & 33 & 3,44 & 87,09 \\
\hline 6 & 55 & 5,73 & 66,14 & 49 & 5,10 & 92,19 \\
\hline 7 & 267 & 27,81 & 93,95 & 26 & 2,71 & 94,9 \\
\hline 8 & 58 & 6,05 & 100,00 & 49 & 5,10 & 100,00 \\
\hline
\end{tabular}

Fonte: COSTA, 1979, p. 47. Obs: \% AC. $=$ \% ACUMULADA

\section{As distintas condições das crianças}

A apreciação dos dados de casamentos consagrados pela Igreja nos lembra uma situação paralela, qual seja, a do batismo de crianças nascidas em distintas situações. Pode-se derivar sugestivas inferências do confronto das curvas de batismos, com base na filiação dos inocentes, a qual compreende três condições distintas: filhos legítimos, naturais e expostos ou enjeitados.

Neste quarto exemplo, nosso foco dirige-se aos expostos, vale dizer, recém-nascidos deixados à porta de residências particulares, igrejas ou do Senado da Câmara, o qual, em Vila Rica, devido ao aumento do número desses rejeitados, viu-se obrigado a auxiliar monetariamente os pais adotivos visando evitar a morte das crianças abandonadas. Nas Cartas Chilenas menciona-se explicitamente o problema gerado pelos gastos com estes párvulos: “Uns dizem, que das rendas do Senado/Tiradas as despesas, nada sobra./Os outros acrescentam, que se devem/Parcelas numerosas impagáveis/Às consternadas amas dos “expostos””. Para efeitos analíticos tomaremos os dados referentes à FNSCAD para o lapso temporal 1719-1818.

A determinação do evoluir no tempo do número e da taxa de enjeitados mostra-se importante, porque nos permite lançar luz sobre as condições econômicas gerais das comunidades estudadas; espera-se, nos períodos de dificuldade econômica ou empobrecimento persistente, o 
aumento da porção dos abandonados, vale dizer, os pais ou a mãe solteira, na impossibilidade de sustentar os filhos - dada a deterioração econômica e a possível ausência de métodos ou práticas anticoncepcionais -, ver-se-iam na contingência de delegar a terceiros a missão de cuidar desses recém-nascidos.

Verificou-se, na aludida paróquia, em termos absolutos, incremento continuado dos expostos do início do período em análise até o lustro 1804-1808; tal aumento numérico assumiu caráter dramático - de quatro rejeitados, batizados no decênio 1724-1733, atingiu-se a cifra de 167 na década 1799-1808. Desta última ao espaço de tempo compreendido entre 1809 e 1818 constatou-se queda substancial - de 167 passou-se a 129 - decorrente, com certeza, do processo emigratório que abatia a população ouro-pretana.

Referentemente ao peso relativo dos rejeitados sobre o total de batismos, observou-se movimento igualmente dramático - de 0,45\% na década 1724-33 chegou-se a cifras que giraram em torno de 11\% no intervalo 1779-1818. Este incremento denuncia um dos aspectos do impacto, sobre as variáveis demográficas, da decadência do exercício da mineração (Cf. FIGURA 1).

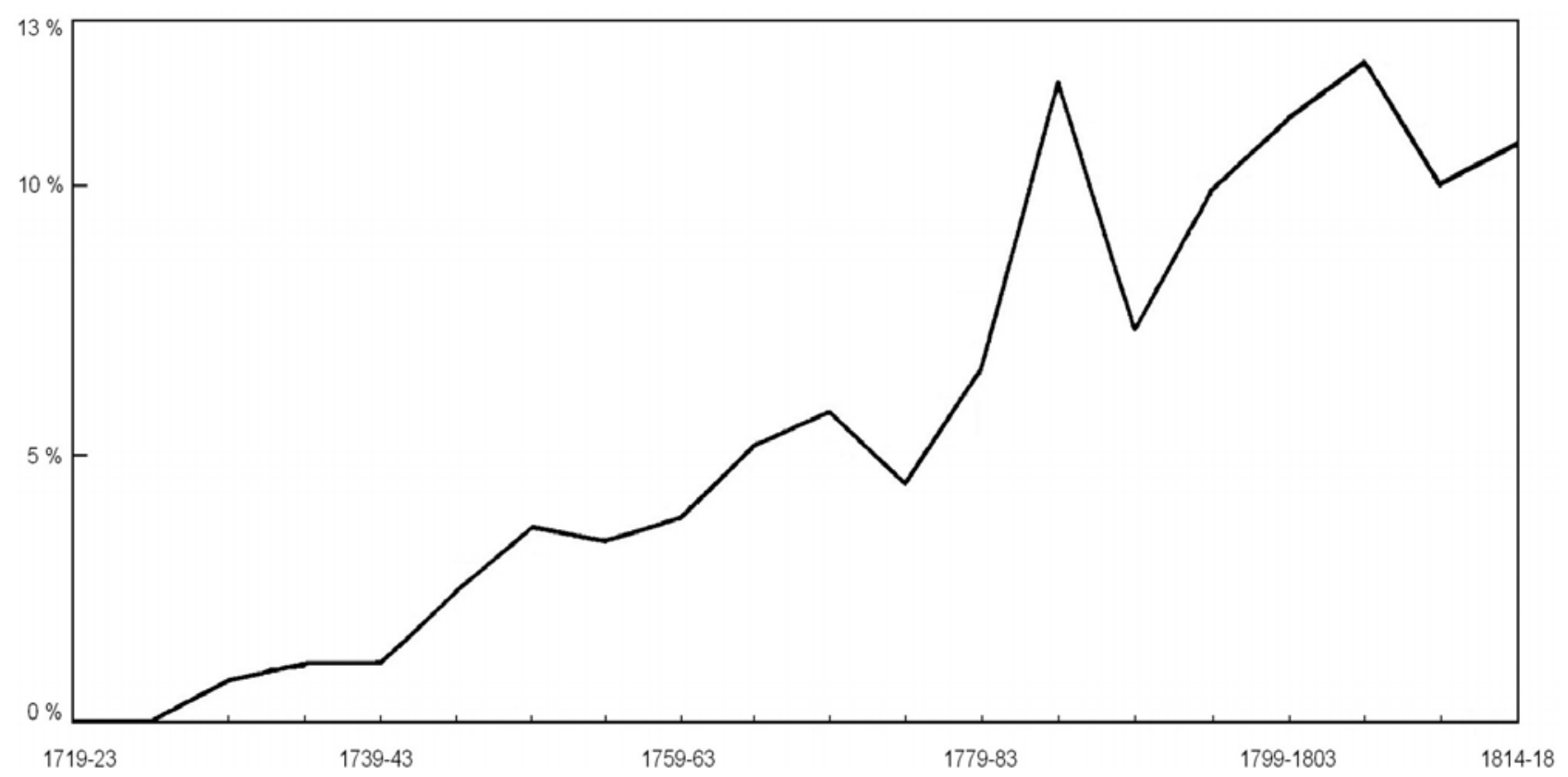

Figura 1 - Porcentagem de batismos de expostos sobre o total de batismos (FNSCAD, 1719-1818, por quinquênios) Fonte: COSTA, 1979, p. 54.

Outro fato expressivo relaciona-se aos porcentuais de enjeitamentos verificados nos subperíodos 1719-1783 e 1784-1818. Nos primeiros 65 anos - 1719-1783 - deram-se, tão somente, 35,96\% do total de rejeições; nos 35 anos restantes (1784-1818), caracterizados pela franca 
Contribuições da demografia histórica para o conhecimento da mobilidade socioeconômica e geográfica: uma aproximação ao tema

decadência econômica de Vila Rica, deu-se o valor complementar, vale dizer, 64,04\% do total de abandonos.

Do supradito resultam duas inferências básicas. A primeira consiste no avolumar-se da quantidade de expostos concomitantemente ao exaustar-se a lida mineradora; como registrado acima, cerca de um terço dos abandonos deu-se nos primeiros dois terços do período estudado; correlatamente, essas proporções reviraram quando se acentuou a crise econômica. A segunda ilação nos leva a notar que, não obstante a queda no número absoluto de expostos, a partir do quinquênio 1804-1808, a fração deles sobre o total de batismos manteve-se em nível muito elevado, pois houve declínio tautócrono no volume global de nascimentos.

\section{Considerações finais}

Segundo nos parece, ficaram demonstradas, ao longo deste artigo, duas evidências maiores: por um lado, a larga abrangência alcançada pelos estudos demográficos voltados à formação histórica de nossas populações, pois, como anotado acima, consideramos que ocorreu entre nós um verdadeiro transbordamento da matéria precípua contemplada pela demografia histórica; de outra parte, é possível detectar-se o quão rico é o acervo de conhecimentos amealhados por nossos demógrafos historiadores, estendem-se eles por um vasto perímetro, abarcando, entre outros, campos tão distintos como a mobilidade social, a dispersão geográfica de nossas populações pretéritas e a condição dos recém-nascidos, a qual se via condicionada pelas vicissitudes defrontadas pela vida econômica de cada localidade.

Dando fecho a estas notas compete-nos acusar seu notório acanhamento, o qual, advirta-se, é devido exclusivamente ao autor e não à capacidade explicativa e às potencialidades da história demográfica.

\section{Para Tito, um amigo que partiu cedo.}

\section{Referências:}

ANAIS do $1^{\circ}$ CONGRESSO de História Nacional, Rio de Janeiro: 1915.

BOXER, C. R. A Idade de Ouro do Brasil. 2a. ed. São Paulo: Cia. Editora Nacional, 1969. (Brasiliana, v. 341).

CARTA DO GOVERNADOR da Capitania do Rio de Janeiro ao Rei, dando as informações determinadas pela provisão de 18 de junho de 1725, relativa aos negros que mais conviriam às 
Minas”, de 5 de julho de 1726. In: Documentos Interessantes, v. 50, Biblioteca Nacional, 1929, p. 60-61.

CARTA RÉGIA estabelecendo novas providências sobre a venda e remessa de escravos Africanos para as Minas, datada aos 27 de fevereiro de 1711. In: Documentos interessantes, n. 49, Arquivo do Estado de São Paulo, 1929.

COELHO, L. C. de M. Mão de Obra Escrava na Mineração e Tráfico Negreiro no Rio de Janeiro, Anais do VI Simpósio Nacional dos Professores Universitários de História (Trabalho Livre e Trabalho Escravo). São Paulo: FFLCH-USP, vol. I, 1973, p. 449-489.

COSTA, I. del N. da. Vila Rica: Mortalidade e Morbidade (1799-1801). In: PELÁEZ, C. M.; BUESCU, M. (Coord.). A Moderna História Econômica. Rio de Janeiro: APEC, 1976. p. 115-127.

COSTA, I. del N. da. Vila Rica: população (1719-1826). São Paulo: IPE-USP, 1979, 268 p. (Ensaios Econômicos, 1).

COSTA, I. del N. da. Algumas características dos proprietários de escravos de Vila Rica. Revista Estudos Econômicos - USP, São Paulo, v. 11, n. 3, p. 151-157, 1981.

FREYRE, G. Casa Grande \& Senzala: formação da família brasileira sob o regime de economia patriarcal. Rio de Janeiro: Maia \& Schmidt, 1933. 517 p. (O prefácio ora citado está disponível em: http://prossiga.bvgf.fgf.org.br/portugues/obra/livros/pref_brasil/casagrande.htm ). Último acesso dia 27. set. 2011.

FURTADO, C. Formação econômica do Brasil. São Paulo: Editora Nacional, 8a. ed., 1968.

MATHIAS, H. G. Um Recenseamento na Capitania de Minas Gerais (Vila Rica - 1804). Rio de Janeiro: Arquivo Nacional, 1969.

RAMOS, A. As Culturas Negras no Novo Mundo. Rio de Janeiro: Civilização Brasileira, 1937, (Biblioteca de Divulgação Científica, v. XII).

RODRIGUES, R. N. Os Africanos no Brasil. 3a. ed. São Paulo: Editora Nacional, 1945. (Coleção Brasiliana, 9).

SALZANO, F. M.; FREIRE-MAIA, N. Populações Brasileiras: aspectos demográficos, genéticos e antropológicos. São Paulo: Editora Nacional e Editora da USP, 1967.

SPIX, J. B. Von; MARTIUS, C. F. P. von. Viagem pelo Brasil. Rio de Janeiro: Imprensa Nacional, 1938. v.3.

Recebido em 10/07/2011

Aprovado em 17/08/2011. 